\title{
LA NATURALEZA COMO MONTAJE TOTAL
}

CÉSAR AIRA, ALEXANDER VON HUMBOLDT Y LA NATURALEZA POSTHUMANA

\author{
Z. Márió Nemes \\ Universidad Eötvös Loránd \\ nemes.z.mario@gmail.com
}

Resumen: El propósito de este estudio es ofrecer una interpretación de la novela corta $U n$ episodio en la vida del pintor viajero (2000) de César Aira, desde el punto de vista del posthumanismo crítico. En este contexto, la noción metodológica central de nuestro acercamiento estético será la denominada "puesta en escena deshumanizante". Las puestas en escena deshumanizantes señalan estrategias poéticas que no son destinadas a presentar la eliminación del principio antropológico, es decir, no representan una abstracción 'más allá del hombre', sino constituyen una puesta en escena de naturaleza estética, durante la cual se introducen tendencias antropomorfizadoras y a la vez desantropomorfizadoras. En esta novela corta de Aira, la relación contradictoria entre naturaleza y sujeto humano es la que sirve como medio de la puesta en escena deshumanizante. A mi modo de ver, emerge al mismo tiempo una dimensión ideológica, dado que el texto describe la intensidad estética que subvierte los órdenes perceptivos y representativos dentro del contexto de la fisionomía de la naturaleza y la pintura del paisaje.

Palabras clave: posthumanismo crítico, puesta en escena deshumanizante, fisionomía de la naturaleza, César Aira, Alexander von Humboldt

\section{NATURE AS A TOTAL MONTAGE CÉSAR AIRA, ALEXANDER VON HUMBOLDT, AND THE CONCEPT OF POSTHUMAN "NATURE"}

\begin{abstract}
The study seeks a critical posthumanist interpretation of César Aira's novel $U n$ episodio en la vida del pintor viajero (2000; An Episode in the Life of a Landscape Painter, 2006). In this context the so-called dehumanizing staging becomes a central methodological concept. Dehumanizing staging refers to different poetic strategies that are not intended to represent the total erasure of the anthropological dimension but constitute an aesthetic performance in which anthropomorphizing and desanthropomorphizing tendencies occur simultaneously. In Aira's novel, the contradictory relationship between nature and the human subject is what serves as the medium of the dehumanizing staging. At the same time, I argue, an ideologically dimension is emerging, as the text depicts the aesthetic intensity that subverts the orders of perception and representation in the reflected context of natural physiognomy and landscape painting.
\end{abstract}

Keywords: critical posthumanism, dehumanizing staging, natural physiognomy, César Aira, Alexander von Humboldt 
DOI: https://doi.org/10.24029/lejana.2020.14.1667

Recibido: el 31 de agosto de 2020

Aceptado: el 8 de octubre de 2020

Publicado: el 26 de febrero de 2021 
En Un episodio en la vida del pintor viajero de César Aira, es dentro de los marcos de una ficción biográfica donde entran en relación conflictiva las nociones básicas de la estética de la (post)modernidad (siendo estas 'paisaje', 'naturaleza', 'representación', 'visión' y 'sujeto'). Se nos da a conocer la historia de un viaje realizado en Argentina del pintor costumbrista de la fisionomía de la naturaleza, Johann Moritz Rugendas, pero a pesar del enmarcamiento histórico concreto, el autor argentino no se deja llevar por una reflexión social o psicológica, pues no coloca en el foco de atención la persona del pintor, el énfasis cae más bien en la correlación noantropocéntrico entre pintura y naturaleza. Con otras palabras, no se trata de una "novela de artista", sino de un texto de humanismo crítico que, mediante la deshumanización de la figura del artista, se propone a examinar las posibilidades de la representación artística tras la "Gran Brecha" (Great Divide, véase Descola, 2011: 99-146), es decir, la relativización de la diferenciación modernista entre la cultura y la naturaleza. Las premisas que servirán de fundamento para mi acercamiento a la obra de Aira son las del posthumanismo crítico, por lo que procuraré subrayar los momentos no-humanistas del texto; no obstante, esto no implica excluir rotundamente del análisis el concepto de lo humano, más bien pretendo aventurarme a deconstruir la orientación antropocéntrica. "Con su punto de partida hibridacionista, mutacionista y el concepto de «devenir otro» entretejido con lo «no-viviente», el posthumanismo vendría a ser una fuente creativa para conocer la alteridad asomada de infinitas formas, ya que refuta la intolerancia hacia la Otredad y la diferencia, característica del ser humano moderno, antropocéntrico y evolucionista" (Horváth-Lovász-Nemes Z., 2019: 33, véase también Nayar, 2014: 79). A lo largo de este proceso pasará a primer plano la "puesta en escena deshumanizante" como noción fundamental metodológica desde el punto de vista estético. Las puestas en escena deshumanizantes señalan estrategias poéticas que no son destinadas a presentar la eliminación del principio antropológico, es decir, no representan una abstracción 'más allá del hombre', sino constituyen una puesta en escena de naturaleza estética, durante la cual se introducen tendencias antropomorfizadoras y a la vez desantropomorfizadoras. A lo largo de esto se revela una "forma intermedia" híbrida donde se asimilan y se 'imitan' códigos, signos y formas humanos-animales-vegetales-mecánicos-etc. Conviene subrayar que esta forma intermedia, que se construye mediante metamorfosis reticuladas, igualmente afecta la estructura de la representación, puesto que, en la puesta en escena deshumanizante, se genera una oscilación entre presencia y ausencia que, en vez de sus momentos miméticos, refuerza los aspectos performativos de la representación. ${ }^{1}$

La puesta en escena deshumanizante propuesta a analizar en el texto de Aira se forma en varios niveles, siendo su momento crucial el accidente de Rugendas con el rayo, que se representa como una suerte de devenir monstruoso. Sin embargo, conviene enfatizar que esta metamorfosis no conlleva una degradación; al contrario, de esta forma, para la Otredad marginada por la ideología del humanismo se propone una posibilidad de apertura hacia lo posthumano. Rugendas únicamente podrá superar sus propios prejuicios y métodos pictóricos humanistas - que hasta entonces han reducido su relación a la naturaleza - siendo monstruo “deshumanizado". Con otras palabras, la deshumanización del artista no solo conduce a la falta y/o ausencia, sino también al nacimiento de una perspectiva no-antropocéntrica que reorganiza

\footnotetext{
${ }^{1}$ Desde esta perspectiva, la puesta en escena deshumanizante viene a interpretarse como la versión posthumanista de la "puesta en escena antropológica" de Iser (2001).
} 
tanto las relaciones entre naturaleza y cultura como los horizontes de lo humano-animal-vegetal que determinan estas mismas relaciones. Esta ruptura, disgregación y subversión será representada en la escena memorable del malón indígena, que destaca también porque en ella se desenvuelve el conflicto entre la naturaleza y el ideal humanista del paisaje dentro de una red compleja de actores humanos y no-humanos. A raíz de todo esto consideramos que la puesta en escena deshumanizante del relato abre un plano ideológico-crítico, ya que escenifica la intensidad estética — que subvierte los horizontes perceptivos y representativos - en correlación con la fisionomía de la naturaleza y la pintura del paisaje. Con esto, la novela presenta dos enfrentamientos: por una parte, el de Rugendas como sujeto deshumanizado y monstruoso frente al ideal humanista del Hombre, y por la otra, el de la naturaleza, de índole eventual e imposible de fijar, frente a los principios totalizantes que pretenden conformar el paisaje pintado. Esta estructura doble de tensiones en conflicto permanente es la que constituye la estructura performativa de la puesta en escena deshumanizante del texto, la maquinaria de acontecimientos textual que representa el malón.

Para poder hablar del entrecruzamiento de estas dos dimensiones de la puesta en escena deshumanizante, primero se debe examinar el fondo estético del procedimiento de la pintura paisajista (véase Levinson, 2014: 49) que determina el método de la creación pictórica y, en última instancia, el modo de ser estético propio de Rugendas.

Rugendas fue un pintor de género. Su género fue la fisionómica de la Naturaleza, procedimiento inventado por Humboldt. Este gran naturalista fue el padre de una disciplina que en buena medida murió con él: la Erdtheorie, o Physique du Monde, una suerte de geografía artística, captación estética del mundo, ciencia del paisaje. Alexander von Humboldt (1769-1859) fue un sabio totalizador, quizás el último; lo que pretendía era aprehender el mundo en su totalidad; el camino que le pareció el adecuado para hacerlo fue el visual, con lo que se adhería a una larga tradición. Pero se apartaba de ésta en tanto que no le interesaba la imagen suelta, el "emblema" de conocimiento, sino la suma de imágenes coordinadas en un cuadro abarcador, del cual el "paisaje" era el modelo. El geógrafo artista debía captar la "fisionomía" del paisaje (el concepto lo había tomado de Lavater) mediante sus rasgos característicos, "fisionómicos", que reconocía gracias a un estudio erudito de naturalista. La calculada disposición de elementos fisionómicos en el cuadro transmitía a la sensibilidad del observador una suma de información, no de rasgos aislados sino sistematizados para su captación intuitiva: clima, historia, costumbres, economía, raza, fauna, flora, régimen de lluvias, de vientos..." (Aira, 2005: 12-13)

En este fragmento se encuentran numerosos momentos conceptuales a base de los cuales el procedimiento puede ser reconstruido, pero conviene subrayar que Un episodio en la vida del pintor viajero igualmente enfatiza la hibridez lingüística, puesto que el texto de la novela se caracteriza de una mixtura tensa de diversos registros, códigos y poéticas genéricos, entre ellos, los del informe de viajes, el tratado científico, la descripción del paisaje, la anécdota y la visión poética. Al mismo tiempo, esta hibridez lingüística se relaciona de nuevo con la herencia de Alexander von Humboldt, dado que la totalidad de la concepción de la ciencia del "sabio totalizador" requiere, visto desde el punto de vista metodológico, de los procedimientos de hibridación. Según esta concepción humboldtiana, las formas representacionales de la totalidad de la naturaleza, del "cosmos", son "pinturas de paisaje" (Naturgemälde) visuales-textuales que aspiran a la mímesis de las formas reticuladas de la naturaleza, por lo cual engloban elementos genéricamente heterogéneos que exhiben las huellas concretas de la experiencia personal, como el informe de viajes, la especulación descriptivo-analítica, la reflexión filosófico-estética, el 
comentario cultural-naturalista, etc. (H. Böhme, 2001: 27). Con este sincretismo estilístico del relato, Aira sigue el principio humboldtiano (al mismo tiempo que procura desenmascarar las contradicciones internas del mismo) que emprende transmitir "la suma de imágenes coordinadas en un cuadro abarcador".

Según considera Joachim Ritter, Alexander von Humboldt es, probablemente, el primer investigador significativo que, en su relación con el cosmos, concibe el descubrimiento y representación estéticos de la naturaleza como 'paisaje' (2007: 129). En este punto conviene aclarar en qué consiste, dentro de este contexto, la diferencia entre 'naturaleza' y 'paisaje'. Ritter observa que la naturaleza como paisaje es un producto del espíritu teorético, una "forma" que es condición previa para la creación de un movimiento doble entre 'trascendencia' y 'distancia', o sea, la creación de un campo de juego para la reflexión. Esta construcción teorético-estética del paisaje es una configuración moderna del concepto filosófico de la 'totalidad de la naturaleza'; a lo largo de esta construcción, el espíritu humano aleja de sí mismo la desfiguración natural en forma de paisaje, y en este distanciamiento reconoce y domestica la desfiguración natural en forma de orden - un todo sensorial-, y por medio de la posibilidad de la experiencia sensorial-conceptual, él mismo (el sujeto) deviene una de sus partes constituyentes. "Paisaje es naturaleza que está presente estéticamente en su contemplación para todo observador dotado de sensibilidad" (Ritter, 1986: 137). Para Humboldt, la experimentación de la naturaleza a través de sus paisajes y su (re)descubrimiento como un todo - cosmos - exige una sintetización entre la estética y las ciencias naturales. No obstante, para poder ratificar la concepción orgánica de la naturaleza (como "unidad en la diversidad", "totalidad viviente", etc. [Ritter, 1986: 141]) y asumirla como formato metafísico del cosmos, a lo largo de las revoluciones decimonónicas de las ciencias naturales no era suficiente la fuerza de la noción filosófica de la inteligencia, sino que esta debía ser complementada con la cosmovisión transmitida por la verdad estética del "observador dotado de sensibilidad". "La naturaleza estética en forma de paisaje ha tomado así a su cargo, en oposición al 'mundo de objetos' de las ciencias naturales, sustraído al concepto metafísico, la función de transmitir y hacer presente para los hombres la totalidad natural y el «acorde armonioso en el cosmos» (Ritter, 1986: 142) en imágenes «plásticas» que han brotado de la interioridad del alma. Para Humboldt, la "captación estética del mundo" (Aira, 2005: 12) no implica el rechazo de la heterogeneidad del mundo empírico (geográfico-biológico) de los objetos, sino más bien una configuración conceptual que, siguiendo la instancia imponente de significados del cosmos, armoniza las escenas locales en paisajes representativos. Esta totalización sensitivo-conceptual de la desfiguración de la materia natural, filtrada por el espíritu humano y dentro de la presencia visible del orden del mundo, llega a ser la tarea central de la fisionomía de la naturaleza.

La palabra fisio(g)nomía viene del griego physis (aquí "naturaleza", "constitución", "carácter") y gnomon (“marca distintiva"). Desde la tradición antigua, a partir de la pseudoaristotélica Fisiognómica, la enseñanza principal de la fisionomía es la interdependencia entre cuerpo y alma, por lo que se puede deducir cómo es la personalidad del ser humano enfocándose en su apariencia externa (la constitución corporal, los rasgos faciales). En este proceso de deducción, la cara tendrá una importancia capital, ya que es un medio tan rico en significados que - a partir del Timeo de Platón — diferencia el hombre del animal, es decir, llega a ser el indicio filosófico-antropológico del ser humano. Desde la antigüedad, a través de la Edad Media y hasta la Edad Moderna, la tradición de la fisionomía cuenta con numerosos autores relevantes, 
basta mencionar el tratado de Giovanni Battista della Porta, De humana physiognomia librit (1570), o las enseñanzas de Paracelso sobre la concepción del micro y el macrocosmos. En su Antropología en sentido pragmático, escrito entre 1789 y 1800, Kant clasifica la fisionomía en la caracterología antropológica. La caracterología examina la cuestión principal de la didáctica antropológica (“¿Qué es el hombre?”) e intenta ofrecer una respuesta a la pregunta ¿Cómo se reconocen las características de las personas?, colocando el énfasis en la manifestación de la personalidad en la apariencia externa de cada uno. En ese análisis, el conocimiento físionómico puede resultar hasta de clave, dado que la fisionomía es "el arte de juzgar por los rasgos visibles de una persona o, en consecuencia, por lo exterior, acerca de su interior; ya se trate de su índole sensible o de la moral" (Kant, 1991: 242). Al mismo tiempo, Kant considera la fisionomía una disciplina contradictoria: no la concibe como ciencia, sino más bien como un medio auxiliar que apoya el cultivo del gusto, que puede estimular a la vez el conocimiento del ser humano mediante el juicio de su moral, las buenas maneras y hábitos, es decir, que ofrece una posibilidad para apropiarse de la cultura de relacional — digno de un cosmopolita — entre los hombres.

En nuestro caso no es tan relevante este dilema político de la filosofía de la ciencia, importa más bien enfatizar que el paradigma fisionómico sugiere la existencia de una relación significante entre un exterior físico y un interior espiritual. La cuestión siempre es cómo la teoría fisionómica vigente determina y qué tipo de relaciones establece entre estas dos dimensiones, y cuál es el estatus de los significados que se intentan generar mediante la "lectura" de las materialidades humana o no-humana. La fisionomía de los siglos XVIII y XIX (probablemente debido a la idea regulativa del orden del mundo de la época) estuvo influenciada por una concepción esencialista de la naturaleza (humana), o sea, la presunción de una verdad identitaria y performativa "interior" que se revelaría tras la lectura "correcta" de la forma "exterior". Esta unión kantiana de la fisionomía y la antropología viene a ser un momento crucial para cuestionar el esencialismo antropológico. Sin embargo, conviene subrayar de nuevo que el papel que desempeña la fisionomía en este proceso es regresivo y, al mismo tiempo, progresivo. Es progresivo porque, con su ayuda, se enfatiza la manifestación del hombre en el mundo vital y su existencia corporal-sensorial, mientras tanto, este mismo énfasis propone una posibilidad para la sensorialidad del hombre de no naturalizarse según el sistema de criterios de la antropología positivista, dado que la fisionomía concibe el ser humano como un entrecruzamiento de aspectos biológicos y culturales. A pesar de esto, subsiste el peligro de que un proyecto cultural-ideológico expropie para sí la lectura del cuerpo y, con esto, "cierre la cara", es decir, que haga de la fisionomía parte de una narrativa del poder. Es por eso que, tras su separación de la fisionomía, la patognomía - una dirección posterior del mismo pensamiento, que examina el carácter performativo de las expresiones corporales - se ha hecho más exitoso; las teorías de la expresión humana trabajan con una concepción dinámica del carácter, mientras que lo mismo no forma parte central de las indagaciones sobre las concepciones posteriores de la antropología filosófica. Este cambio tiene que ver con la revisión antropológica de la (auto)identicidad del ser humano y de la relación mimética entre cuerpo y alma.

La fisionomía de la naturaleza humboldtiana igualmente posibilita la lectura de la naturaleza no-humana aunque, a raíz del pensamiento del cosmos, la naturaleza humana cuenta con una relevancia determinante; a lo largo de la visibilización de la presencia estética del orden del mundo, la cara humana (su "verdad") y el paisaje natural (su "verdad") se exigen 
mutuamente. Por eso afirma Gernot Böhme que esta indagación estética de la naturaleza siempre tiene que ver con el hombre, o sea, es antropocéntrica: apunta al descubrimiento de formas naturales cuyo valor o significado, desde el punto de vista de la percepción humana, es atmosférico (1995: 142). Por lo tanto, la mirada fisionómicamente constituida del paisajista no pretende representar 'el aquí y el ahora' de la experiencia de la naturaleza sino, sobrepasando la disformidad "exterior", quiere leer el carácter oculto pero típico del paisaje, y así, fijar la “impresión total” (Totaliendruck). La revelación sensorial del carácter atmosférico del paisaje presupone el conocimiento de la tipología de las formas vegetales básicas que, desde el punto de vista de la indagación fisionómica, también conlleva la preferencia de ciertos territorios geográficos:

Sólo en los trópicos se encontraba el exceso necesario de formas primarias para caracterizar un paisaje. En la vegetación, Humboldt había reducido estas formas primarias a diecinueve; diecinueve tipos fisionómicos, cosa que no tenía nada que ver con la clasificación linneana, que opera con la abstracción y el aislamiento de las variaciones mínimas; el naturalista humboldtiano no era un botánico sino un paisajista de los procesos de crecimiento general de la vida. Ese sistema, a grandes rasgos, constituía el "género" de pintura que practicó Rugendas. (Aira, 2005: $15-16)$

La preferencia humboldtiana de los paisajes trópicos implica uno de los conflictos principales del texto; Rugendas parte para el viaje argentino porque, contrariamente a los consejos de sus maestros, quiere aplicar el procedimiento para plasmar el "vacío misterioso" de las pampas (Aira, 2005: 12). Se trata pues de una hibris o rebelión metodológica, debido a la cual el accidente del rayo se interpretaría como una suerte de castigo. ${ }^{2}$ El sujeto del pintor aparece subordinado al procedimiento humboldtiano, ya que debe servir el descubrimiento total de la naturaleza siendo una especie de maquinaria creadora de imágenes; de esta forma, se encubre una perspectiva deshumanizadora en su relación con la naturaleza: para revelar la cara de la naturaleza, el artista sacrifica su propia individualidad artística o, metafóricamente, su propia cara. Mientras tanto, el sensorio humano del pintor viene a ser medio imprescindible del "éxito" del método, y así, el devenir Máquina Fisionómica será un obstáculo antropológico interior. A pesar de esto, la revelación experimentada en la pampa materializa la pérdida metafórica de la cara, puesto que este suceso — que se genera en una vacuidad y apertura radicales_ puede surgir únicamente si se destruyen las estructuras materiales y espirituales de la subjetividad humana.

El derrumbe imposible del trueno lo envolvió en millones de ondas. El caballo bajo sus piernas empezó a girar. No terminaba de hacerlo cuando le cayó un rayo en la cabeza. Como una estatua de níquel, hombre y bestia se encendieron de electricidad. Rugendas se vio brillar, espectador de sí mismo por un instante de horror, que lamentablemente habría de repetirse. La crin del caballo estaba toda parada, como la aleta de un pez espada. A partir de ese momento se volvió una visión extraña para sí mismo, como sucede en las catástrofes personalizadas, cuando uno se pregunta: ¿Por qué tuvo que pasarme a mí? (Aira, 2005: 45)

A lo largo de la puesta en escena deshumanizante, se producen varios éxtasis polimorfos: los agentes que pertenecen a diversos horizontes existenciales dejan atrás su propia forma

\footnotetext{
${ }^{2}$ Contrariamente a lo que aparece en la novela, Humboldt no rechazó rotundamente los altiplanos, por ejemplo, en su texto titulado "Über die Steppen und Wüsten" (Sobre estepas y desiertos) representa elocuentemente la fisionomía de las pampas. Véase G. Böhme, 1995: 27.
} 
identitaria. El movimiento "contranatural" del caballo amenaza con la pérdida de ser-caballo y vivir-como-caballo, mientras que es tanta la fuerza animadora de la electricidad que logra generar una figura heterogénea nueva: "una estatua de níquel, hombre y bestia". Es decir, los límites materiales y ontológicos (muerto-vivo) vienen a ser difusos, es más, esta retícula de metamorfosis podrá ser interpretada como una estructura de cyborgización posthumana. En esta indeterminación formal pulsante de electricidad cualquier fisionomía perdería su fuerza ordenadora, puesto que las formas plásticas y la mirada modeladora que se vuelve desfijada no son capaces de sincronizarse en la unidad orgánica de la naturaleza "compartida". La mirada humana se desorganiza cuando Rugendas, siendo su propio espectador, se convierte en su propio espectáculo ajeno, y la posibilidad de una impresión total se desvanece en el torbellino informe de los fragmentos no-antropocéntricos de la naturaleza. De modo paradójico, esta escisión de la mirada desantropomorfiza, pero a la vez también antropomorfiza, ya que el pintor es incapaz de reconocerse como Rugendas en el híbrido 'hombre-caballo-estatua de níquel', a la par que justo es en este acontecimiento imposible de personificarse es donde reconoce su propia individualidad superada.

Por eso considera Brett Levinson que el encuentro de Rugendas con la disformidad y la fuerza deformadora de las pampas genera, para él, una especie de renacimiento; sin embargo, su transformación no se concebiría como recomienzo, ya que la pérdida de su ser anterior para siempre se inscribe en su cara, mejor dicho, en el "lugar" de su cara, en forma de ausencia. Según la perspectiva del posthumanismo crítico, nunca será posible dejar atrás las estructuras humanistas; estas, en forma de sedimentos o huellas, seguirán acompañando a los discursos que desean negarlas o superarlas rotundamente (véase Badmington, 2003). Rugendas deviene monstruo, pero su monstruosidad no implica algo 'más allá de lo humano', sino más bien una perspectiva excéntrica, desde donde el carácter construido de la modernidad humanista se ve como posible de desenmascarar. "Uno se acostumbra a cualquier deformidad, hasta la más horrenda, pero cuando se le suma un movimiento incontrolable de los rasgos, un movimiento fluido y sin significado, el hábito se resiste a instalarse, comprensiblemente" (Aira, 2005: 63). Desde el punto de vista de la fisionomía, la cara en movimiento incontrolable, que actúa como herida viva, llega a ser un ruido imposible de interpretar; no obstante, debido a la sujeción antropomorfizadora inevitable, debemos reconocerla como la cara de un ser humano, pero de modo contradictorio, este reconocimiento es imposible. Esta disonancia antropológica se caracteriza como 'no-acostumbrable'; es el ser liminal irritante del monstruo. Pero esta 'noacostumbrabilidad' asimismo cuenta con otro aspecto: el espectáculo de la cara monstruosa, que se convierte en máscara, hace entrar en sospecha las caras humanas que la contemplan y que quizás son, también, máscaras. Dentro de la estructura visual humanista, esta "superficie" fisionómicamente ilegible, que oscila entre lo humano y lo no-humano, se expande como un virus, puesto que su "movimiento fluido y sin significado" llega a plantear la duda fundamental de que la concepción 'cuerpo-alma' — analogía del modelo 'significante-significado' — será insostenible frente a los fenómenos monstruosos.

La metamorfosis posthumana de Rugendas no llega a eliminar el procedimiento: el pintor-monstruo no reniega del método, sino lo transfigura destacando y transformando sus fragmentos parciales. Una de sus nuevas observaciones es que

el procedimiento fisonómico operaba con repeticiones: los fragmentos se reproducían tal cual, cambiando apenas su ubicación en el cuadro. Si no era fácil notarlo, ni siquiera por el que lo 
hacía, era porque el tamaño del fragmento variaba inmensamente, desde el punto al plano panorámico (podía desbordar mucho al cuadro). Y además, en su trazado, podía ser afectado por la perspectiva. Tan pequeño y tan grande como el dragón. (Aira, 2005: 56)

Enfatizar las "repeticiones" conduce a separar cada vez más los "fragmentos" visuales de cualquier tipo de relación representacional que estas mantienen con la naturaleza real, es decir, reconduce la forma visual hacia sí mismo, siendo Rugendas una estructura inmanente de creación de imágenes.

Esta idea podía presidir una concepción totalmente distinta de la realidad. En su trabajo, Rugendas había empezado a notar que cada trazo del dibujo no debía reproducir un trazo correspondiente de la realidad visible, en una equivalencia uno a uno. Por el contrario, la función del trazo era constructiva. De ahí que la práctica del dibujo siguiera siendo irreductible al pensamiento, $\mathrm{y}$ a pesar de la completa incorporación del procedimiento, le fuera posible seguir dibujando. (Aira, 2005: 62-63)

Conviene subrayar de nuevo que el carácter no-mimético se encuentra previamente inscrito en los principios humboldtianos; la abstracción tipificadora es la garantía de la existencia de una relación entre el escenario concreto y las formas básicas de la naturaleza, es decir, Rugendas no procede contrariamente al método, sino - radicalizando sus momentos constructivos - 10 invierte desde dentro. Así logra revelar imágenes que hasta entonces no se han visto, que no se parecen, aluden o refieren a "nada", aunque sí se constituyen de la repetición de formas "conocidas"; de este modo, esta repetición exagerada llega a cobrar un carácter performativo, puesto que ella misma constituye su propia referencia.

El ensayo general de esta superación es el retrato del malón indígena, que le preocupa a Rugendas ya antes del accidente con el rayo y que clasifica, dentro de la estructura de los temas a pintar, junto al terremoto. La analogía es sumamente sugestiva, ya que desnaturaliza el malón cuando lo describe como "tifón humano" que no obedece a las normas culturales. Esta colocación de los indígenas en el ámbito de la naturaleza se concebiría como una exotización a partir de la modernidad eurocéntrica, sin embargo, no se trata de una simple deshumanización étnica. ${ }^{3}$ Desde la perspectiva del posthumanismo, lo importante es el malón como conocimiento, y no los indígenas como pueblo; el malón es una catástrofe que viola las fronteras, ya que desmorona las delimitaciones modernistas entre la naturaleza y la cultura (Horn, 2014: 15). Las acciones compenetrantes del ataque, el contraataque, la defensa, etc. establecen una estructura reticulada que involucra cuerpos, materiales, idiomas y sujetos muy diversos. Juntar las reses, transmitir las informaciones, construir el fuerte y elaborar las tácticas conlleva la hibridación de agentes, prácticas y cuerpos que asimila hasta el proyecto pictórico de Rugendas y de su colega Krause. Mientras que la ecología performativa del malón impide la diferenciación entre naturaleza y cultura, el procedimiento tampoco puede desligarse del objeto de la representación. Ambos pintores se posicionan dentro del acontecimiento, no son capaces de asumir una posición exterior, ya que ellos mismos están sujetos tanto al cambio de velocidad de las acciones como a la continuidad de las escenas. "El detalle que les interesaba era la fugacidad, la organización en el azar, la velocidad de organización. El procedimiento del combate indios-

\footnotetext{
${ }^{3}$ La manifestación del contexto (post)colonial de la mirada fisionómica humboldtiana es una posibilidad interpretativa relevante del texto. Véase Sachs (2003) y Levinson (2014: 47-50).
} 
blancos se reproducía en el de los pintores: había un equilibrio de cercanías y lejanías al que había que sacarle el máximo provecho" (Aira, 2005: 81).

El malón indígena como puesta en escena deshumanizante se vincula con la revelación generada por el rayo, porque es donde Rugendas puede experimentar, inscrito en su propio cuerpo, el conflicto entre naturaleza y paisaje. Podemos observar que, dentro del contexto del método fisionómico antropocéntrico, para el hombre, el paisaje es una unidad de significado formada tras la mediación estética del ser humano. No obstante, desde la perspectiva del posthumanismo, la naturaleza es una estructura autosuficiente, dinámica y abierta pero sin núcleo o centro idéntico; en ella, los límites entre lo físico y lo no-físico, y entre lo orgánico y lo no-orgánico son porosos, lo que al mismo tiempo implica la naturalización de la cultura y el carácter constructivo de la naturaleza (Weber, 2003: 226). Comparando con este modelo híbrido e informe, el paisaje (o su imagen) aparece como producto cultural homogéneo que exhibe la superioridad imponente de significados de la imagen humanista del ser humano frente a los horizontes de existencia no-humanos. Se trata, evidentemente, de una concepción del paisaje reducida, que comprende la representación de la naturaleza como paisaje como herramienta estética de la domesticación ideológica. Como indica el cuestionamiento interior de la fisionomía humboldtiana de la naturaleza de parte de Aira, las estéticas del paisaje portan señas ideológicas simultáneas pero contradictorias. Rugendas, en vez de poner en escena el paisaje no-plástico del malón, representa la disgregación de las formas del paisaje en repeticiones de intensidad heterogénea.

El doble estatus de los indígenas indica el colapso de las estructuras miméticas: no simplemente devienen imágenes con la ayuda del pintor, sino son de antemano simulaciones teatrales. Su comportamiento guerrero y sus posturas corporales son "inverosímiles", ya que su táctica principal es la intimidación y la ostentación de su fuerza. Suponen un desafío mayor para Rugendas, que no puede leer fisionómicamente estos gestos corporales; en vez de sugerir intenciones, motivaciones o rasgos de carácter, simplemente favorecen la programación de la atmósfera del acontecimiento. En vez de tener significado, cuentan con una impresión de significado que no puede ser fijado dentro de naturaleza humana estática alguna, dado que se insertan como forma autorreferencial y sensorial entre los mecanismos teatrales del malón.

Estas escenas eran mucho más de cuadros que de la realidad. En los cuadros se las puede pensar, se las puede inventar; con lo cual pueden sobrepasarse en extrañeza, en incoherencia, en locura. En realidad, en cambio, suceden, sin intervención previa. Frente al Tambo estaban sucediendo, y a la vez era como si se estuvieran inventando a sí mismas, como si manaran de las ubres de las vacas negras. (Aira, 2005: 89)

Esta opacidad de los gestos corporales encuentra su contrapunto asimétrico en la cara-máscara monstruosa de Rugendas. El pintor no puede ser centro y productor del malón indígena, siendo esta una estructura visual, ya que - tal como se ha dicho anteriormente - la disgregación performativa de las posibilidades del paisaje elimina la dominancia de la mirada humanista. En cambio, se trata de una maquinaria deshumanizada que apunta todo y que está sujeta a la ecología teatral de los agentes humanos y no-humanos. Pero esta sujeción, esta mezcla informe entre la imagen y la mirada que la constituye, este devenir "mal dibujado" es lo que facilita para Rugendas poder tener parte en la actuación del malón "más allá” del paisaje. El procedimiento, por lo menos en su forma pura, no posibilita lo mismo: 
El procedimiento humboldtiano era un sistema de mediaciones: la representación fisionómica se interponía entre el artista y la naturaleza. La percepción directa quedaba descartada por definición. Y sin embargo, era inevitable que la mediación cayera, ni tanto por su eliminación como por un exceso que la volvía mundo y permitía aprehender al mundo mismo, desnudo y primigenio, en sus signos. (Aira, 2005: 96-97)

Esta descripción es contradictoria, puesto que la desnudez deseada no es, simplemente, una evidencia contrapuesta a la mediación, sino es una inmediatez mediada que justo se crea a partir del exceso de la mediación. Brett Levinson comparte esta opinión al afirmar que aquí se trata de la autosuperación de la forma humboldtiana: el estilo supera el medio que le ha sido capacitado para "estilizar" (2014: 58). La cara monstruosa de Rugendas no es la "exteriorización" de algo "interior", ni la mediación entre lo verdadero y lo falso; es el envolvimiento, el anudamiento de lo informe interior y exterior en sí mismo, sobre una superficie desnuda. Por lo tanto, el exceso de la mediación llega a crear la autorreferencia plana del estilo, a partir de la cual será imposible interpretar la dialéctica fisionómica de lo superficial y lo profundo, lo exterior y lo interior, lo verdadero y lo falso; a pesar de esto, para que esta misma inmanencia pueda constituirse, se han requerido los marcos predisponentes por el método. Es dentro de este contexto donde se esclarece que el malón, como acontecimiento tanto teatral y no-mimético, es "plano" debido a que todas las dicotomías jerárquicas requeridas por la fisionomía antropocéntrica "se aplanan" en la repetición deformadora de la puesta en escena deshumanizante. La impresión total de la imagen del paisaje llega a ser el montaje total entre el artista y la naturaleza.

Traducción de Petra Báder*

\section{Bibliografía}

AIRA, César (2005): Un episodio en la vida del pintor viajero. Barcelona, Mondadori.

BADMINGTON, Neil (2003): “Theorizing Posthumanism”. Cultural Critique, 53: 10-27. DOI: http://dx.doi.org/10.1353/cul.2003.0017

BÖHME, Gernot (1995): Atmosphäre. Frankfurt am Main, Suhrkamp Verlag.

BÖHME, Hartmut (2001): "Ästhetische Wissenschaft. Aporien der Forschung im Werk Alexander von Humboldts". En Ottmar Ette-Bernd M. Scherer-Christian Suckow (eds.): Alexander von Humboldt - Aufbruch in die Moderne. Berlin, De Gruyter: 17-33.

DESCOLA, Philippe (2011): Jenseits von Natur un Kultur. Berlin, Suhkramp Verlag.

HORN, Eva (2014): Zukunft als Katastrophe. Frankfurt am Main, Fischer Verlag.

HORVÁTH Márk-LOVÁSZ Ádám-NEMES Z. Márió (2019): A poszthumanizmus változatai - Ember, embertelen és ember utáni. Budapest, Prae.

ISER, Wolfgang (2001): A fiktívés az imaginárius. Trad. Gábor Tamás Molnár. Budapest, Osiris.

KANT, Immanuel (1991): Antropología en sentido pragmático. Trad. José Gaos. Madrid: Alianza Editorial.

\footnotetext{
*Agradezco enormemente la revisión del texto traducido a Luis Gustavo Meléndez Guerrero - P. B.
} 
--- (2005): "Pragmatikus érdekủ antropológia". Antropológiai írások. Ford. Miklós Mesterházi. Budapest, Osiris Kiadó: 7-306.

LEVINSON, Brett (2014): "Procedures for Drawing the Event of the Indians. On Aira's An Episode in the Life ot a Landscape Pintor". The New Centennial Review XIV/1: 47-70. DOI: https://doi.org/10.14321/crnewcentrevi.14.1.0047

NAYAR, Pramod K. (2014): Posthumanism. Cambridge UK-Malden, Polity Press.

RITTER, Joachim (1986): "El paisaje. Reflexiones sobre la función de lo estética en la sociedad moderna”. En Subjetividad. Seis ensayos. Trad. Rafael de la Vega. Barcelona, Alfa: 125158.

--- (2007): “A táj - Az esztétikum funkciója a modern társadalomban”. Trad. Zoltán Papp. En Tamás Miklós (ed.): Szubjektivitás - Válogatott tanulmányok. Budapest, Atlantisz Könyvkiadó: 113-143.

SACHS, Aaron (2003): "The Ultimate «Other». Post-Colonialism and Alexander von Humboldt's Ecological Relationship with Nature". History and Theory LXII/4: 111-135. DOI: https://doi.org/10.1046/j.1468-2303.2003.00261.x

WEBER, Jutta (2003): "Vom Nutzen und Nachteil posthumanisitscher Naturkonzepte". En Gernot Böhme-Alexandre Manzei (eds.): Kritische Theorie der Technik und der Natur. München, Wilhelm Fink Verlag: 221-247.

(C) Z. Márió Nemes

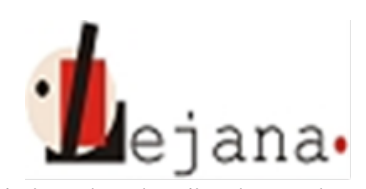

http://ojs.elte.hu/index.php/lejana

Universidad Eötvös Loránd, Departamento de Español, 1088 Budapest, Múzeum krt. 4/C 